\title{
An anatomical and MRI assessment of the of anterolateral ligament.
}

\author{
Yong Qin ${ }^{1}$, Ming Li², Songcen Lv', Haile Pan ${ }^{1}$ * \\ ${ }^{1}$ Orthopedic Surgery Section 4, the $2^{\text {nd }}$ Affiliated Hospital of Harbin Medical University, Harbin, PR China \\ ${ }^{2}$ Department of Sports Trauma and Arthroscopic Surgery, Zhengzhou Orthopaedics Hospital, Zhengzhou, PR China
}

\begin{abstract}
Background: Characterize the anatomy of the Anterolateral Ligament (ALL) in fresh donated knees and as viewed using MRI imaging within knees.

Methods: The ALL was dissected from the 8 fresh donated knees. Both dissections of fresh cadaver knees and MRI imaging were used to provide a description of the anatomical features and projections of the ALL as well as the conditions for optimal imaging of this structure.

Results: The ALL was identified in all but one of the $8(87.5 \%)$ knees. It originates from the fibular condyle of the femur and courses anterolaterally to the tibial plateau. The ALL width within the tibial plateau was $7.42 \pm 0.80 \mathrm{~mm}, 8.56 \pm 0.59 \mathrm{~mm}$ and $10.53 \pm 0.51 \mathrm{~mm}$ within the different in footprints of the ALL in the femur and tibia. The thickness within the tibial plateau was $1.29 \pm 0.03 \mathrm{~mm}$. The length of the ALL was $33.93 \pm 1.81 \mathrm{~mm}$. When using 3.0 T MRI, the ALL could be clearly identified within coronal positions of the 7 fresh cadaver knees.

Conclusion: We show that the ALL courses along the anterolateral side of the knee, originating in the condylus lateralis femoris and terminating in the tibial plateau. The ALL projects superior to, and connects with, the lateral meniscus. It seems likely, that a clearer image of the ALL could be achieved with a flexion of the knee at $60^{\circ}$.
\end{abstract}

Keywords: Anterolateral ligament, Anatomy, MRI.

Accepted on December 26, 2017

\section{Introduction}

In 1879, Paul [1] described a 'pearly, resistant, fibrous band' located at the anterolateral aspect of human knee. Terry et al. $[2,3]$ considered this structure to be a periost bundle of the iliotibial tract, while Hughston [4,5] described this structure as a (mid-third lateral) capsular ligament. Investigators involved with the study of this structure have named it the 'anterior band of the lateral collateral ligament' [1] and 'anterior oblique' band [6]. In 2013, Steven et al. [7] reintroduced the anatomical characteristics of this ligament and named it the Anterolateral Ligament (ALL) $[8,9]$. As a result, a renewed interest in the study of the ALL ensued as assessed using anatomical, histological and X-ray analyses, however, very limited information is available in which MRI was applied to the study of the ALL.

\section{Methods}

\section{Identification of $A L L$}

We inspected the knees of 8 donated fresh knees. Dissection of the anterolateral aspect of the human knee was performed to locate the ALL. Once identified, the ALL from within the lateral capsule in the anteromedial and anterolateral surfaces of the ALL were photographed.

\section{Anatomical analyses}

The characteristics of the ALL were investigated in 8 fresh donated knees. These included 6 males and 2 females with a mean age of 52.14 y at death (ranges of 45-66 y) and involved 2 left and 6 right knees. An identical dissection procedure was used for each knee consisting of skin and hypodermis removal followed by a midline dissection of the joint and separation of the patellar ligament from the tibial tuberosity. The extensor apparatus and cruciate ligaments (ACL and PCL) were removed. The iliotibial tract was resected at the insertion site of Gerdy's tubercle and the fibular head. The ALL could now be observed from its origin at the external condyle of femur and its anterolateral course to the tibial plateau. Once the entire extent of the ALL was isolated and identified, measures of its width in the femoral and tibial footprint, width and thickness in the tibial plateau and length were recorded.

\section{MRI analyses}

MRIs of 7 fresh donated knees (one of the 8 cases failed to show an ALL). Identical MRI parameters were used in the identification of the ALL. The version of MRI used was the Siemens MAGNETOM Trio 3.0 T Series 9: 1 T1W_aTSE SENSE; scan duration: 2:39; number of images: 10; TSE/SE; TE $20 \mathrm{~ms}$, TR $500 \mathrm{~ms}$; flip $90^{\circ}$. 
A Philips shower was used to analyse the series. Analyses were conducted in the coronal plane proceeding from the posterior to anterior direction using the FCL and popliteal tendon as an anatomical landmark for locating the ALL. The knee was fixed at $0^{\circ}, 15^{\circ}, 30^{\circ}$ and $60^{\circ}$ respectively.

\section{Results}

\section{Identification of $A L L$}

In the 8 fresh donated knees examined, an ALL was identified in 7 (87.5\%) knees. The one knee lacking an ALL was a male whose knee was injured in an accident. Although the ALL may have been damaged in the accident, no apparent residue of an ALL was present. Therefore, while a damage-induced destruction of the ALL cannot be completely ruled out, we presume that no ALL was present in this case.

\section{Anatomical analyses}

In the 7 cases where an ALL was identified, the, ALL originates from the fibular condyle of femur and courses anterolaterally to the tibial plateau. When the ALL was found to course through the lateral meniscus we could readily identify a connection between the ALL and lateral meniscus (Figure 1). Table 1 contains a summary of the measures performed on these 7 knees. ALL widths in the tibial plateaus were $7.42 \pm 0.80 \mathrm{~mm}, 8.56 \pm 0.59 \mathrm{~mm}$ and $10.53 \pm 0.51 \mathrm{~mm}$ at the footprints of ALL in the femur and tibia, respectively. ALL thickness in the tibial plateau was $1.29 \pm 0.03 \mathrm{~mm}$. While, ALL length was $33.93 \pm 1.81 \mathrm{~mm}$.

\section{MRI analyses}

In knees of donated fresh knees, MRI analyses were performed when their knees were flexed at $0^{\circ}, 15^{\circ}, 30^{\circ}, 60^{\circ}$, then a clear ALL was identified at $0^{\circ}$, more ALL parts could be readily identified when knee was flexed at $60^{\circ}$ (Figure 2).
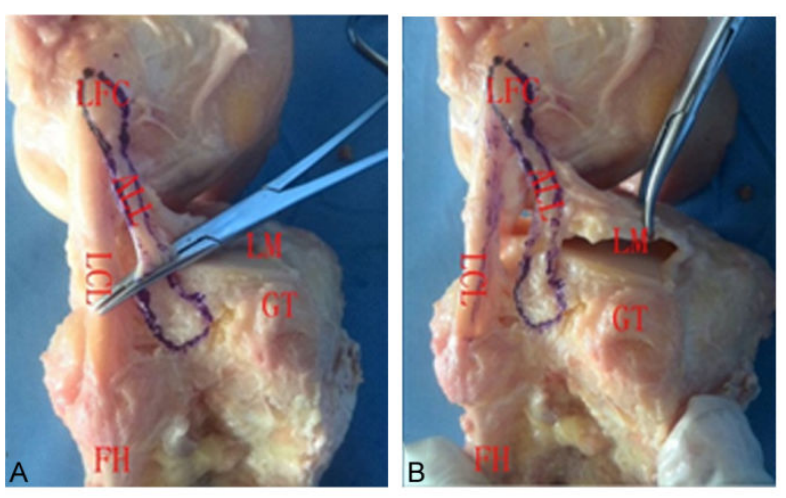

Figure 1. Photographs of the ALL. A: ALL originated from the fibular condyle of femur and coursed anterolaterally to the tibial plateau. B: ALL connected with the lateral meniscus. LFC: Condylus Lateralis Femoris; ALL: Anterolateral Ligament; LCL: Lateral Collateral Ligament; LM: Lateral Meniscus; FH: Fibular Head; GT: Gerdy's Tubercle.

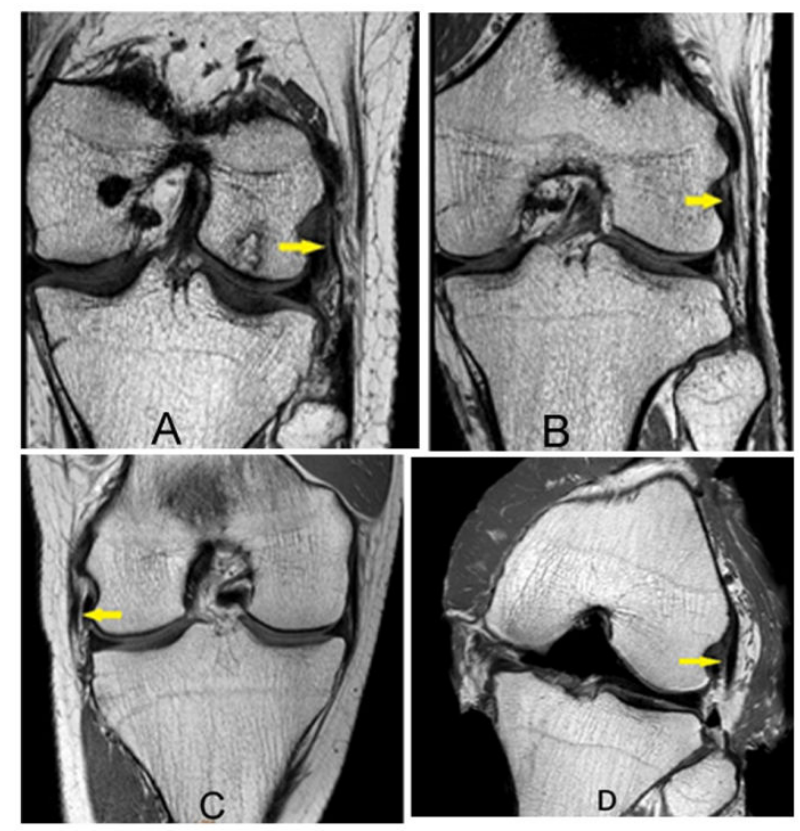

Figure 2. The knee was fixed at $0^{\circ}(A), 15^{\circ}(B)$, or $30^{\circ}(C)$ or $60^{\circ}(D)$. Yellow arrow indicates the ALL. As indicated in these images, the $A L L$ was more clearly evident when the knee was flexed at $60^{\circ}(D)$.

Table 1. The data of the anatomy of ALL.

\begin{tabular}{|c|c|c|c|c|c|c|c|}
\hline \multirow[t]{2}{*}{ S. no } & \multirow[t]{2}{*}{ Age } & \multirow[t]{2}{*}{ Gender } & \multirow[t]{2}{*}{ Length } & \multicolumn{3}{|l|}{ Width } & \multirow[t]{2}{*}{$\begin{array}{l}\text { Thickness in } \\
\text { tibial plateau }\end{array}$} \\
\hline & & & & In femur footprint & In tibial plateau & In tibia footprint & \\
\hline 1 & 45 & Male & 36.5 & 9.62 & 6.73 & 11.27 & 1.28 \\
\hline 2 & 50 & Male & 33.5 & 8.31 & 7.91 & 10.14 & 1.26 \\
\hline 3 & 48 & Female & 34.7 & 8.94 & 7.46 & 10.73 & 1.26 \\
\hline
\end{tabular}




\begin{tabular}{|c|c|c|c|c|c|c|c|}
\hline 4 & 66 & Male & 31.2 & 8.45 & 6.32 & 10.2 & 1.29 \\
\hline 5 & 56 & Male & 35.4 & 8.43 & 8.45 & 11.14 & 1.34 \\
\hline 6 & 48 & Female & 33.9 & 8.49 & 8.15 & 9.91 & 1.27 \\
\hline 7 & 52 & Male & 32.3 & 7.7 & 6.89 & 10.3 & 1.32 \\
\hline Average & 52.14 & & 33.9 & 8.56 & 7.42 & 10.53 & 1.29 \\
\hline Standard deviation & 7.03 & & 1.81 & 0.59 & 0.8 & 0.53 & 0.03 \\
\hline Mean square & 49.48 & & 3.28 & 0.35 & 0.63 & 0.28 & 0.001 \\
\hline
\end{tabular}

\section{Discussion}

Since originally introduced by Segond [10] in 1879, the existence and description of the Anterolateral Ligament (ALL) has appeared in numerous reports but has been fraught with confusion regarding its exact anatomy and name. A degree of consistency was established in 2013 when Clases [7] reintroduced a more precise description of the anatomy of this ligament and designated it as the Anterolateral Ligament (ALL). While a number of studies on the ALL have been performed using a variety of techniques, few have applied MRI as a means to assess this structure [11]. In this report, MRI was used to identify and characterize the ALL within fresh donated knees. Our results demonstrate that the ALL can be recognized with MRI in these cases.

In all but one of the 8 knees of fresh cadavers examined $(87.5 \%)$ was it possible to locate and dissect the ALL. The one case in which we failed to locate an ALL involved a male that had been injured in a car accident. However, we felt this accident had little effect, as no ALL residue was found in this case. Therefore, we concluded that no ligament was present. This conclusion is consistent with other information in the literature indicating that not all knees may have an ALL. For example, while Scott Caterine et al. [12] found ALLs in all knees dissected, Dodds [13] found ALLs in only $83 \%$ of their knees and Clases [7], who reintroduced the ALL in 2013, reported that $97 \%$ of the knees they studied had an ALL.

On the basis of our anatomical analyses, we observed that the ALL originates at the lateral condyle of the femur and courses anterolaterally to the tibial tuberosity. While Alex [14] reported 2 variations in the footprint of the ALL in the femur, we did not observe such variations, which might be due to our small sample size. We did observe a connection between the ALL and lateral meniscus, which was also seen by many other investigators. Under arthroscopy, Sonnery-Cottet [15] observed the ALL to connect with the lateral meniscus as it passed though the lateral meniscus. Our anatomical findings of the ALL are consistent with descriptions provided from previous research on the ALL.

The ALL within the knees could be readily located with MRI. When the knee was flexed at $60^{\circ}$, the ALL was more perceptible than that at $0^{\circ}$. Steven et al. studied the ALL only when the knee was flexed at $0^{\circ}$. The ALL could be more readily identified when the knee was flexed at $0^{\circ}$ or $30^{\circ}$ versus that when flexed at $15^{\circ}$. Based upon our findings that the ALL could be seen more clearly when the knee was flexed at $60^{\circ}$.

As the ALL consists of a ligament confined to the anterolateral aspect of the knee (Figure 1), the observation of this ligament in its entirety will be limited. Steven [16] noted that the entire ALL will seldom be found within a monolayer of tissue. When assessing the coronal and sagittal planes of the knees with MRI, we found it difficult to identify the ALL within the sagittal plane. The ALL could more easily be seen within the coronal plane and the ALL within a knee flexed at $0^{\circ}$ could be identified more readily, but usually cannot be seen in a single MRI image. According to our results, it appears that an optimal observation of the ALL can be achieved with the knee flexed at $60^{\circ}$.

In summary, we show that the ALL courses along the anterolateral side of the knee, originating in the condylus lateralis femoris and terminating in the tibial plateau. The ALL projects superior to, and connects with, the lateral meniscus. It seems likely, that a clearer image of the ALL could be achieved with a flexion of the knee at $60^{\circ}$.

\section{Conflict of Interest}

The authors declare that they have no conflict of interest.

\section{References}

1. Irvine GB, Dias JJ, Finlay DB. Segond fractures of the lateral tibial condyle: brief report. J Bone Joint Surg $\mathrm{Br}$ 1987; 69: 613-614.

2. Terry GC, LaPrade RF. The posterolateral aspect of the knee. Anatomy and surgical approach. Am J Sports Med 1996; 24: 732-739.

3. Terry GC, Norwood LA, Hughston JC, Caldwell KM. How iliotibial tract injuries of the knee combine with acute anterior cruciate ligament tears to influence abnormal anterior tibial displacement. Am J Sports Med 1993; 21: 55-60.

4. Hughston JC, Andrews JR, Cross MJ, Moschi A. Classification of knee ligament instabilities. Part I. The medial compartment and cruciate ligaments. J Bone Joint Surg Am 1976; 58: 159-172.

5. Hughston JC, Andrews JR, Cross MJ, Moschi A. Classification of knee ligament instabilities. Part II. The 
lateral compartment. J Bone Joint Surg Am 1976; 58: 173-179.

6. Campos JC, Chung CB, Lektrakul N, Pedowitz R, Trudell D, Yu J, Resnick D. Pathogenesis of the Segond fracture: anatomic and MR imaging evidence of an iliotibial tract or anterior oblique band avulsion. Radiology 2001; 219: 381-386.

7. Claes S, Vereecke E, Maes M, Victor J, Verdonk P, Bellemans J. Anatomy of the anterolateral ligament of the knee. J Anat 2013; 223: 321-328.

8. Herbst E, Albers M, Burnham JM, Fu FH, Musahl V. The Anterolateral Complex of the Knee. Orthop J Sports Med 2017; 5: 2325967117730805.

9. Zhu YL, Qi C, Li CH, Zhao X, Yu TB. Anatomical and histological study of anterolateral ligament of knee. China J Sports Med 2017; 36: 472-478.

10. Segond P. Recherches cliniques et experimentales sur les epanchements sanguins du genou par entorse. Progres Medical (Paris).(accessible from http: // www.patrimoine.edilivre.com/).

11. Faruch Bilfeld M, Cavaignac E, Wytrykowski K, Constans O, Lapegue F, Chiavassa Gandois H, Larbi A, Sans N. Anterolateral ligament injuries in knees with an anterior cruciate ligament tear: Contribution of ultrasonography and MRI. Eur Radiol 2018; 28: 58-65.

12. Caterine S, Litchfield R, Johnson M, Chronik B, Getgood A. A cadaveric study of the anterolateral ligament: re- introducing the lateral capsular ligament. Knee Surg Sports Traumatol Arthrosc 2015; 23: 3186-3195.

13. Dodds AL, Halewood C, Gupte CM, Williams A, Amis AA. The anterolateral ligament: Anatomy, length changes and association with the Segond fracture. Bone Joint J 2014; 96: 325-331.

14. Rezansoff AJ, Caterine S, Spencer L, Tran MN, Litchfield RB, Getgood AM. Radiographic landmarks for surgical reconstruction of the anterolateral ligament of the knee. Knee Surg Sports Traumatol Arthrosc 2015; 23: 3196-3201.

15. Sonnery-Cottet B, Archbold P, Rezende FC, Neto AM, Fayard JM, Thaunat M. Arthroscopic identification of the anterolateral ligament of the knee. Arthrosc Tech 2014; 3 : 389-392.

16. Claes S, Bartholomeeusen S, Bellemans J. High prevalence of anterolateral ligament abnormalities in magnetic resonance images of anterior cruciate ligament-injured knees. Acta Orthop Belg 2014; 80: 45-49.

\section{${ }^{*}$ Correspondence to}

Haile Pan

Orthopedic Surgery Section 4

The $2^{\text {nd }}$ Affiliated Hospital of Harbin Medical University

PR China 